\title{
Reduced DC Circuit Breaker Requirement on Mixed Converter HVDC Networks
}

\author{
Geraint Chaffey, Tim C. Green \\ Electrical and Electronic Engineering Department \\ Imperial College London \\ London, UK \\ Email: g.chaffey12@imperial.ac.uk
}

\begin{abstract}
Recently proposed meshed HVDC networks include both converters and DC circuit breakers, however the fault currents experienced and therefore the capacity requirement of circuit breakers are dependent on the topology of converters used on the network. This paper analyses the difference in fault currents seen in various network configurations utilising fault feeding and fault blocking converters. Results are presented showing the reduced fault currents seen in the regions of the DC network where fault current limiting converters have been implemented, which has a direct impact on the topology, current rating and and therefore size and cost of the circuit breaker.
\end{abstract}

Index Terms-HVDC transmission, Circuit breakers, Fault protection, AC-DC power converters.

\section{INTRODUCTION}

Multi-terminal HVDC (MTDC) networks are increasingly likely to be essential to future energy networks, providing efficient bulk transfer of renewable energy across continents whilst providing reliability through redundancy. A key technical hurdle is the DC fault challenge; faults on the DC network propagate quickly, drawing large currents that must be rapidly isolated to protect sensitive converter stations and to allow power transfer to resume. This paper analyses the impact of converter topology on fault currents observed on MTDC networks, and therefore the Circuit Breaker (CB) capacity requirement for line fault protection.

Several topologies of converter have been proposed for implementation on future HVDC networks, however when regarding analysis of a DC fault there is a clear divide with regards to fault response. Many converter topologies are sensitive to a DC side low impedance fault (providing an uncontrolled fault current from the $\mathrm{AC}$ side of the converter to the DC side), however some converter topologies are fault current blocking (with the ability to block and/or limit the current into a fault). Whilst the Modular Multi-level Converter (MMC) can be constructed from either half-bridge or fullbridge cells, the increased losses of the full-bridge MMC mean it seems likely that only the half-bridge version will ever draw investment, excluding special cases. The half bridge MMC, shown in Fig 1(a), is unable to fully control the

The authors gratefully acknowledge the sponsorship and support of EDF R\&D UK Centre and the EPSRC.

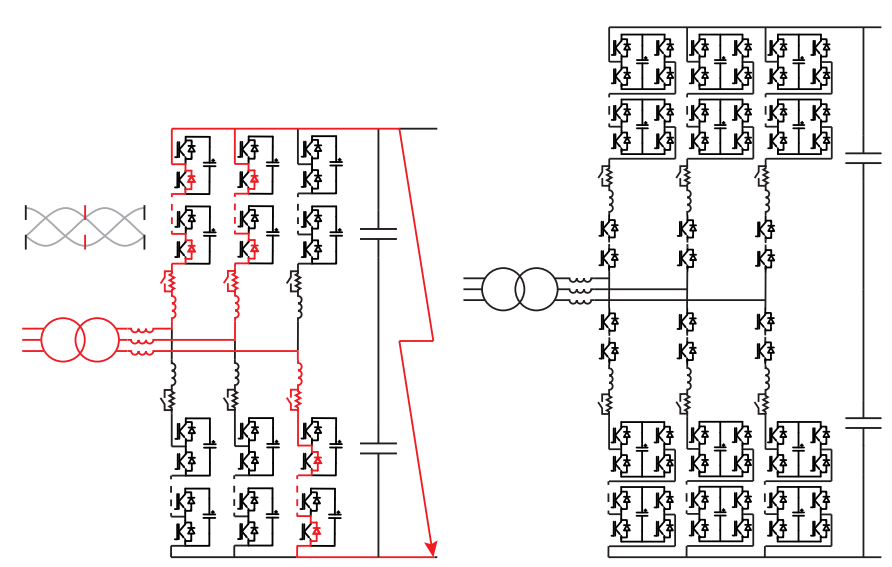

(a) Modular multilevel converter

(b) Alternate arm converter

current into a fault once the DC voltage falls below the AC voltage peak. Conversely, the Alternate Arm Converter (AAC), shown in Fig 1(b), is a hybrid MMC-style topology, consisting of full bridge capacitor cells in series with semiconductor switches operating such that each arm is nominally only in conduction for half the fundamental AC cycle [1]. Given the implementation of full bridge cells, the AAC is capable of fully controlling the current from the $\mathrm{AC}$ to the $\mathrm{DC}$ side in the event of a DC side low impedance fault.

There are several fast DC CB topologies that have been proposed and are presently under test which are expected clear a fault in the region of $5 \mathrm{~ms}$ [2]-[4]. There is also the more established resonant style $\mathrm{CB}$, expected to be capable of clearing a fault in approximately $20 \mathrm{~ms}$. It is expected that the hybrid style CB will be significantly more complex with a higher volume and mass than the resonant style CB. Many proposed protection schemes suggest implementing a hybrid CB at each end of each transmission line or cable on the DC network. The options for reducing the requirement on the $\mathrm{CB}$ by implementing fault current limiting converters on at least one of the network nodes is discussed in the following sections. 


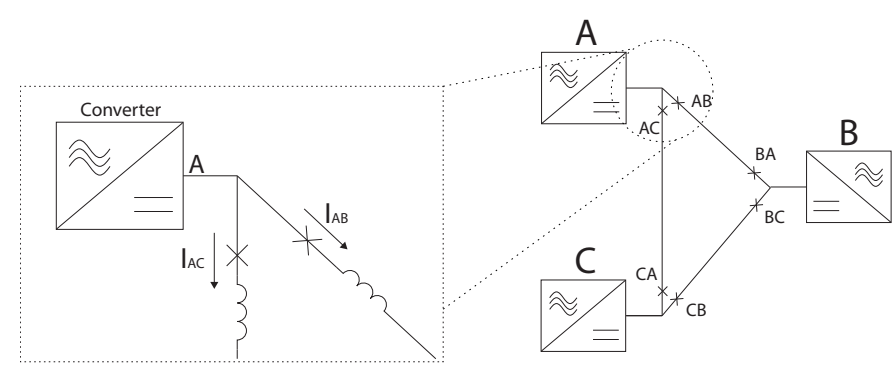

Fig. 2: Three terminal symmetric network where single line diagram represents bipolar breaker and cable arrangement (200 km per line)

\section{Modelling Methodology}

Observed fault currents are dependant on the converter, cable and fault parameters. Models have been developed to simulate a $\pm 525 \mathrm{kV}$ HVDC network, with each converter rated at a nominal $2.4 \mathrm{GW}$, values that have been chosen to represent the highest power cable based meshed network that might feasably be constructed given the present state of technology. Full switching converter models and wideband frequency dependant lines have been implemented in order to accurately represent each element of the model, as described below. Fault tests are conducted using a $0.5 \Omega$ fault impedance from pole to pole. A $100 \mathrm{mH}$ fault current limiting inductance has been implemented at each end of each line, in common with breaker specification [5] and many published protection schemes, e.g. [6], [7].

\section{A. Converter Models}

According to the relevant design constraints and optimisations [8], [9], MMCs with half bridge capacitor cells and AACs with full bridge capacitor cells have been modelled, where the cell capacitors and inductors have also been sized accordingly. Coverter parameters are detailed in Table I. The AAC has additional series director switches, modelled as a chain of IGBTs. Each converter has been modelled using SimPowerSystems and the Opal RT Artemis blockset within Matlab/Simulink.

\section{B. Cable Model}

Cable dimensions have been evaluated for the highest power cable commercially avaliable at the time of writing, a $525 \mathrm{kV}$ extruded DC cable with a $3000 \mathrm{~mm}^{2}$ stranded copper conductor capable of transmiting $2.6 \mathrm{GW}$ through one pair of

TABLE I: Converter Parameters

\begin{tabular}{ccc}
\hline & MMC & AAC \\
\hline $\mathrm{S}_{\text {BASE }}$ & $2.4 \mathrm{GW}$ & $2.4 \mathrm{GW}$ \\
$\mathrm{V}_{\text {DC }}$ & $\pm 525 \mathrm{kV}$ & $\pm 525 \mathrm{kV}$ \\
$\mathrm{V}_{\text {AC }}$ & $643 \mathrm{kV}$ & $816 \mathrm{kV}$ \\
$\mathrm{I}_{\text {DC }}$ & $2260 \mathrm{~A}$ & $2260 \mathrm{~A}$ \\
$\mathrm{~N}_{\text {CELL }}$ & 75 & 64 \\
\hline
\end{tabular}

TABLE II: Three terminal network configurations

\begin{tabular}{cccc}
\hline Case & Converter A & Converter B & Converter C \\
\hline 1 & MMC & MMC & MMC \\
2 & MMC & MMC & AAC \\
3 & MMC & AAC & AAC \\
4 & AAC & AAC & AAC \\
\hline
\end{tabular}

cables [10]. Based upon the published manufaturer data the extruded insulator layer has been estimated to have a radial thickness of $25.0 \mathrm{~mm}$ [11]. Aside from the conductor and insulation layer the construction of the cable is highly similar to a lower voltage extruded HVDC cable, and as such all other layers of the cable have been modelled using parameters originally derived for $300 \mathrm{kV}$ extruded DC cable, as presented in [12]. In the absence of detailed parameters from the cable manufacturer this is an appropriate approximation for conducting system level studies. The shield is earthed through a $10 \Omega$ resistance at each termination, and the armour is directly connected to ground.

The cable is modelled in EMTP-RV as a wideband (frequency dependant phase model) line, the most advanced line model that is commercially available [12]-[14]. The model is then imported into Matlab/Simulink by using the frequency dependant wideband line included in the Opal RT ARTEMiS Simulink blockset. This modelling method has been validated using industry standard software PSCAD and EMTP-RV.

\section{ANALYSis OF DC-Side Low IMPEDANCE FAUlTS}

In the scope of this paper only pole to pole faults are considered, as these may produce the most challenging conditions from the circuit breaker prespective when purely considering the peak current. The choice between Overhead Lines (OHL) and cables is vital in order to determine the impact of transients on the DC network; in particular with regards to faults the wave speed has a key influence on the fault current observed. Due to social and enviromental pressures, future transmission networks are expected to consist mostly of sub-terrainian and sub-sea cables, therefore within the scope of this paper only cables have been considered.

\section{A. MMC Fault Response}

Under a DC low impedance fault the half bridge MMC contributes an uncontrolled current through the diode path indicated in red in Fig 1(i). In order to protect the lower anti-parallel diode within each capacitor cell from overcurrent damage, each capacitor cell contains a thyristor bypass so that in the event of an overcurrent the cell can be bypassed. The bypass thyristor has a far greater peak current capacity, and the majority of the fault current is commutated given the lower on-state impedance.

In the absence of a suitable $\mathrm{DC} \mathrm{CB}$, the only means to isolate the fault current is via the $\mathrm{AC} C B$, which might be expected to be capable of disconnecting the converter from the AC grid in several fundamental cycles. The fault 
current consists of the initial capacitor discharge, followed by the fault current fed by the converter, in addition to the current contributed from cable capacitance and distant sources. The converter control system detects the fault and orders the opening of the $\mathrm{AC} \mathrm{CB}$, which occurs on a phase by phase basis at the next zero crossing after a breaker operating delay. It is desirable to isolate a fault from the DC side of the converter, given that if the $\mathrm{AC} \mathrm{CBs}$ are opened the the converter station will take an extended period of time to re-synchronise with the $\mathrm{AC}$ grid and resume power transfer. In order to determine breaker requirements, $\mathrm{AC}$ side protection has been disabled in order to determine maximum $\mathrm{CB}$ capacity requirements such that the network can be protected by DC CBs.

\section{B. AAC Fault Response}

Given that each arm of the AAC only conducts for approximately half a fundamental $\mathrm{AC}$ cycle the number of capacitor cells required is able to be reduced, allowing the AAC to compare well to the losses of the MMC whilst providing control benefits, including the capability to control the current into a DC fault. Given this capability, there are benefits when considering MTDC networks. During a DC side fault, after the DC bus capacitor discharges there is no uncontrolled fault current contribution from the converter, whilst reactive power support can be provided to the AC network.

\section{DC Circuit Breaker Capabilities}

Whilst recently published DC circuit breaker topologies have demonstrated a capability to inturrupt current of appropriate magnitude in the millisecond timescale [3], [5], their implementation on a network is still to be fully evaluated. Given the complexity of the proposed devices it is likely that they will be of a considerable size and cost, and given that the semiconductor switches within the breaker are highly sensitive to overcurrent, capacity requirements must be carefully evaluated. It is also reasonable to assume that the size and cost of each circuit breaker will be partly dependant on the current breaking capability. Other technologies have been implemented in applications such as load transfer switches (e.g. resonant topologies), however these technologies are not presently thought to be capable of operating in the very short timescales required in proposed DC networks consisting wholly of fault feeding converters.

\section{Circuit Breaker Duty on Multi-Terminal NETWORKS}

The requirement for circuit breakers is dependent on the network topology to be protected. Given that a point to point link will no longer be able to transfer power if the link is faulted, it is acceptable to isolate the fault using the $\mathrm{AC}$ side circuit breakers, however when considering multi-terminal meshed network configurations it becomes desirable to be able to isolate individual lines without isolating the entire network. Given the dependence of the CB cost and size on the current interruption capabilities, mechanisms to reduce the breaker duty may be of interest. The expected interruption capabilities
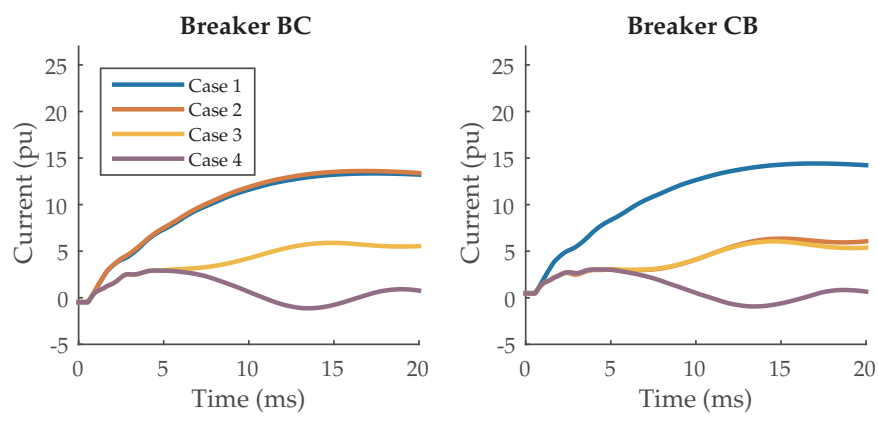

Fig. 3: Fault current at the circuit breaker, showing comparison of three terminal networks with a variety of converter topologies, where lines are $200 \mathrm{~km}$ from converter to converter, fault $100 \mathrm{~km}$ from converter $\mathrm{C}$ on line $\mathrm{B}-\mathrm{C}$
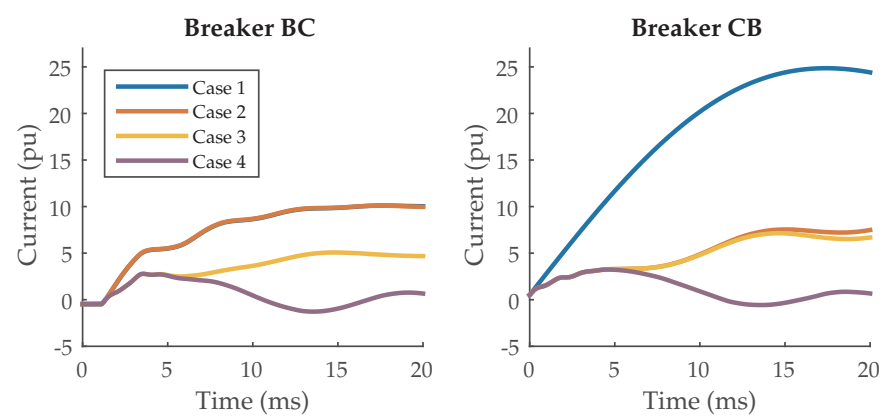

Fig. 4: Fault current at the circuit breaker, showing comparison of three terminal networks with a variety of converter topologies, where lines are $200 \mathrm{~km}$ from converter to converter, fault $0 \mathrm{~km}$ from converter $\mathrm{C}$ on line $\mathrm{B}-\mathrm{C}$

required of breakers on a variety of network configurations have been evaluated in the following sections.

\section{A. Three Terminal Meshed Networks}

In order to determine the impact that converter topology has on fault conditions on meshed networks, a three terminal system has been simulated. A fault mid-way down the longest line on a network of fault feeding converters might typically be considered a less severe fault, however when considering a network with one or more fault blocking converters a fault at the terminal of the $\mathrm{CB}$ may be significantly less severe, if an AAC is at that network node. Four network configurations, Table II, have been simulated on the three terminal network shown in Fig 2.

An example of the fault currents observed under differing converter configuration is shown in Fig 3, in which a fault condition $100 \mathrm{~km}$ along line A-C has been examined. It can be seen that there is a $66 \%$ decrease in the peak fault current at breaker $\mathrm{CB}$ in case two (in which an AAC is implemented at terminal C). As this is mid-way along the line it might normally be considered a less severe fault, so a full analysis has been conducted on a variety of fault locations. Fig 4 shows the breaker currents observed from a fault at the breaker terminal of line $\mathrm{C}-\mathrm{B}$, in which the current observed from a 


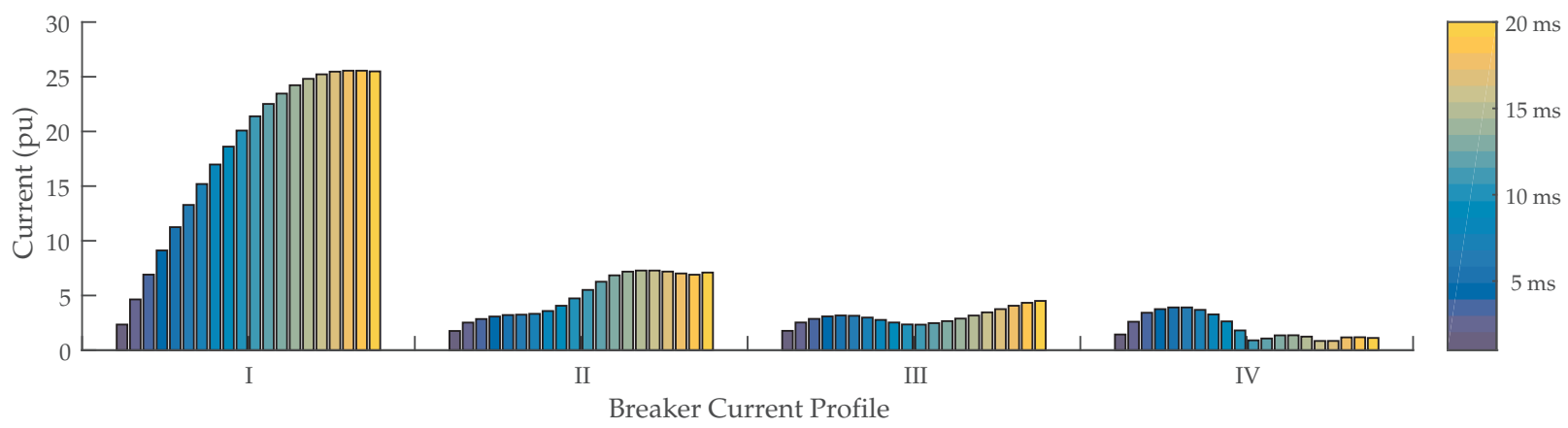

Fig. 5: Three terminal mixed converter network: peak breaker current profiles aggregated from all fault scenarios. Each profile represents the current seen at a CB where; (I) MMC at local node, (II) AAC at local node, MMC one segment away, (III) AAC at local node, AAC one segment away, MMC two segments away, (IV) AAC at each node.

wholly MMC network rises steeply and reaches 11 pu in $5 \mathrm{~ms}$. A fault case such as this is typically part of the justification given for the requirement for fast hybrid CBs. Examining the fault current observed in case one where one converter has the ability to fault block, there is a $64 \%$ reduction in the fault current observed after $5 \mathrm{~ms}$, and after $20 \mathrm{~ms}$ the fault current only rises to $7.47 \mathrm{pu}$. This is due to the additional impedance of the lines and breaker inductors, limiting the rate of rise of the fault current. In this case a slower CB topology might be well suited at this location.

Due to line reflections the peak fault current is not always observed from the closest fault to the breaker [15], therefore a series of fault studies have been conducted in order to determine an accurate peak breaker requirement. A fault case has been simulated at each converter terminal and every $10 \mathrm{~km}$ along each line, with the results being aggregated to form a peak breaker current profile as a time variant maximum of current for each breaker.

On the three terminal symmetrical network there are four distinct circuit breaker profiles that have been observed, depending on the placement of MMCs and AACs across the network, as shown in Fig 5. The peak breaker current profile is dependant on converter locations, line length, number of adjacent lines and the breaker inductance. This profile represents the time variant peak breaker current that could be expected to occur at the given breaker location, and therefore is a reasonable measure from which to determine circuit breaker requirements.

a) Breaker profile I: The current profile observed is shown when the converter at the adjacent node to the $\mathrm{CB}$ is an $\mathrm{MMC}$, and therefore the fault current in-feed is dominated by the local converter. A CB in this position would be required to operate in the $5 \mathrm{~ms}$ time scale to protect the adjacent converter, given the high rate of rise of current.

b) Breaker profile II: This current profile occurs when the converter at the adjacent node to the $\mathrm{CB}$ is an $\mathrm{AAC}$, which feeds no current into the fault from the AC side. The fault current is therefore dominated by the nearest MMC, one network segment away from the breaker. Given the larger impedance of the line and the breaker inductors, the fault current rises significantly slower than profile I. A CB in this position would not be required to operate in the $5 \mathrm{~ms}$ time scale, given that the peak breaker current observed only reaches $7.28 \mathrm{pu}$ in the first $20 \mathrm{~ms}$ following the fault, best suiting a slower resonant CB topology.

c) Breaker profile III: The current profile shown occurs when both the converter at the adjacent node to the breaker and the converter one network segment away are AACs, and the converter two network segments away is an MMC. In this scenario the fault current is limited by additional impedance, and therefore rises slowly. A CB in this position would also not be required to break in the $5 \mathrm{~ms}$ timescale; given that the peak current observed in the first $20 \mathrm{~ms}$ proceeding the fault is $4.50 \mathrm{pu}$ it would also be appropriate to implement a resonant CB topology in this position.

d) Breaker profile IV: This current profile is observed when every converter on the network is an AAC, therefore after the discharge of the DC bus capacitors no current is fed to the fault. A fast and/or high capacity circuit breaker in this position is not required given that there is no fault current to be broken, as the current can be controlled by the converters across the network. A fast disconnector in this breaker position would be sufficient to isolate a faulted line and allow the remaining network to resume power transmission.

\section{B. Five Terminal Meshed Networks}

In order to examine a more representative example of a large network, a five terminal network has been evaluated with a variety of line lengths and converters, Fig 7, on the network described in Table III. Fault studies have first been conducted on a network consisting wholly of MMCs as a 'base case', then converters have been selected to be converted to an AAC, in order to compare the fault response and breaker requirement across the network and investigate the impact of a low level of peneteration of fault blocking converters.

a) Converter comparison at node B: The peak breaker current profiles for node B, Fig 6 , show that there is a reduction in the breaker current requirements at this node when an AAC is implemented (black outline) rather than an MMC (red outline) at the node. Average currents are reduced by $62 \%$ after 


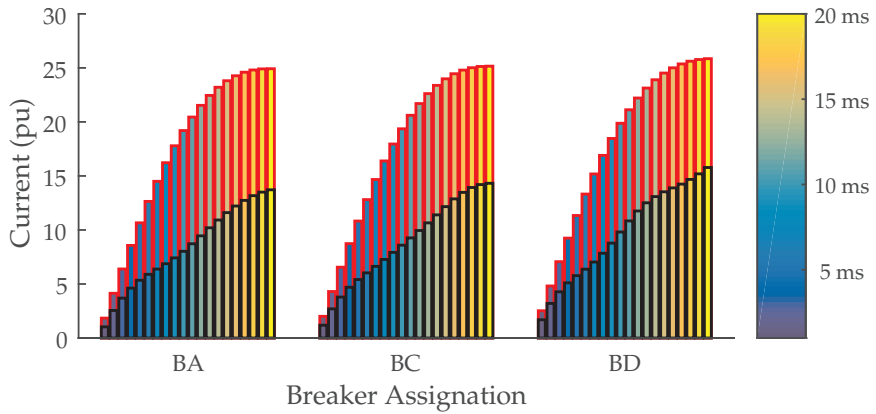

Fig. 6: Summary of five terminal fault studies; Aggregated peak fault current seen at the breaker where converter $B$ is an AAC (black outline) and an MMC (red outline)

$5 \mathrm{~ms}$, and $45 \%$ after $20 \mathrm{~ms}$. The profile is similar across each breaker at the node, indicating that the line length does not have a significant impact on the breaker requirements, due to the large $\mathrm{CB}$ inductors that dominate the fault current response. Breakers in these positions would benefit from a less severe constraint on the operating time and/or a reduction in the $\mathrm{CB}$ inductor required.

b) Converter comparison at node E: Given that node $\mathrm{E}$ has the least interconnection to other converters and has the longest lines on the network, it is interesting to consider the case to implement an AAC at this location. The peak breaker current profiles, Fig 8, exhibit a significantly lower rate of rise, and after $20 \mathrm{~ms}$ the current has only risen to a maximum magnitude of $7.51 \mathrm{pu}$. It may be appropriate to implement slower resonant syle $\mathrm{CB}$ topologies in these locations, given that the breaker requirements are significantly less severe.

c) Converter comparison at node $C$ : The impact of replacing the converter at node $\mathrm{C}$ has also been evaluated, Fig 9. It can be seen that there is a reduction in the peak breaker current profiles, leading to a reduction in the requirements of a breaker at the locations around node $\mathrm{C}$. It is likely that implementing a fault current limiting converter here would allow a significant reduction in the $\mathrm{CB}$ inductors. Although an $\mathrm{AAC}$ at this location only has a minor impact on the

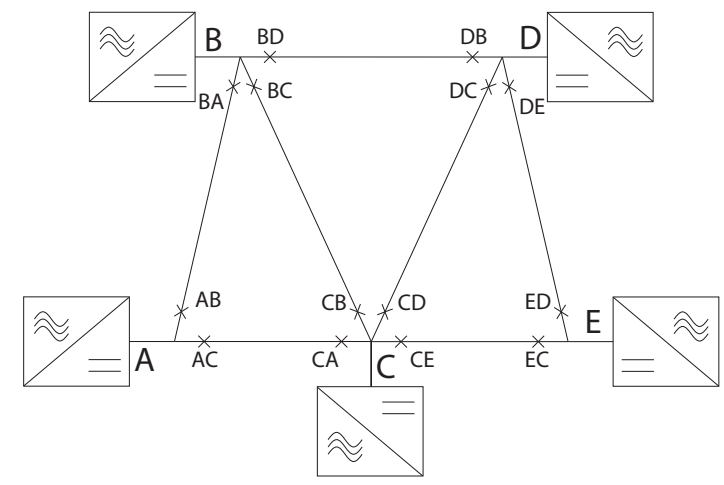

Fig. 7: Five terminal network where single line diagram represents bipolar breaker and cable arrangement

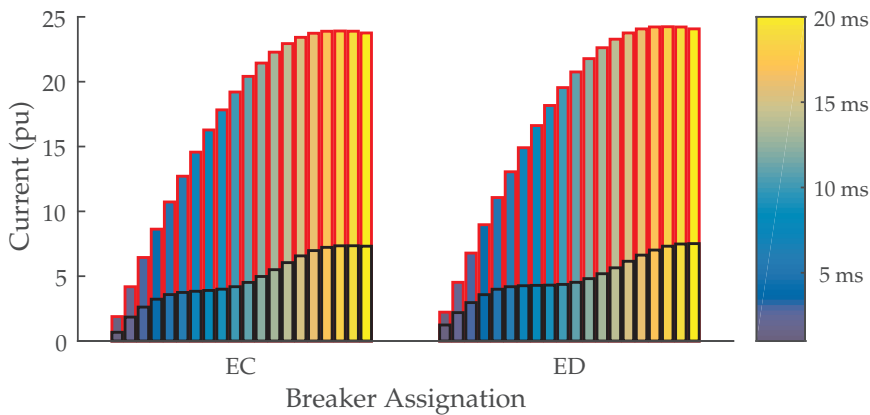

Fig. 8: Summary of five terminal fault studies; Aggregated peak fault current seen at the breaker where converter $\mathrm{E}$ is an AAC (black outline) and an MMC (red outline)

prospective breaker requirements, it is likely to lead to a reduction in current limiting inductance across 4 CBs. The response here is dominated by the large in-feed provided to the fault by the large amount of interconnection at this node.

\section{CONCLUSION}

Given that fast HVDC CBs and associated high energy air cored inductors are expected to have significant volume, mass, and ultimately cost, it is important to examine ways to optimise their implementation across a network. By implementing a variety of converter topologies across a network, it becomes feasable to reduce the breaker duty in some locations and opens up the possibility for less complex resonant CB topologies to be applied. This may in particular have a significant role when considering volume restricted applications on offshore platforms. It has been shown that implementing fault current limiting converters at some or all of the nodes on a network can sigificantly improve DC fault conditions and may lead to a reduction in $\mathrm{CB}$ requirements.

\section{REFERENCES}

[1] M. Merlin, T. Green, P. Mitcheson, D. Trainer, D. Critchley, and R. Crookes, "A new hybrid multi-level voltage-source converter with dc fault blocking capability," in AC and DC Power Transmission, 2010. ACDC. 9th IET International Conference on, Oct 2010, pp. 1-5.

[2] M. Callavik, A. Blomberg, J. Häfner, and B. Jacobson, "The hybrid hvdc breaker," ABB grid system, Technical paper Nov, 2012.

[3] W. Grieshaber, J.-p. Dupraz, D. L. Penache, and L. Violleau, "Development and test of a $120 \mathrm{kV}$ direct current circuit breaker," CIGRE session 2014,2014

TABLE III: Five terminal network: line lengths

\begin{tabular}{cc}
\hline \hline Line & Length $(\mathrm{km})$ \\
\hline A-B & 120 \\
A-C & 85 \\
B-C & 170 \\
B-D & 310 \\
C-D & 255 \\
C-E & 350 \\
D-E & 295 \\
\hline
\end{tabular}




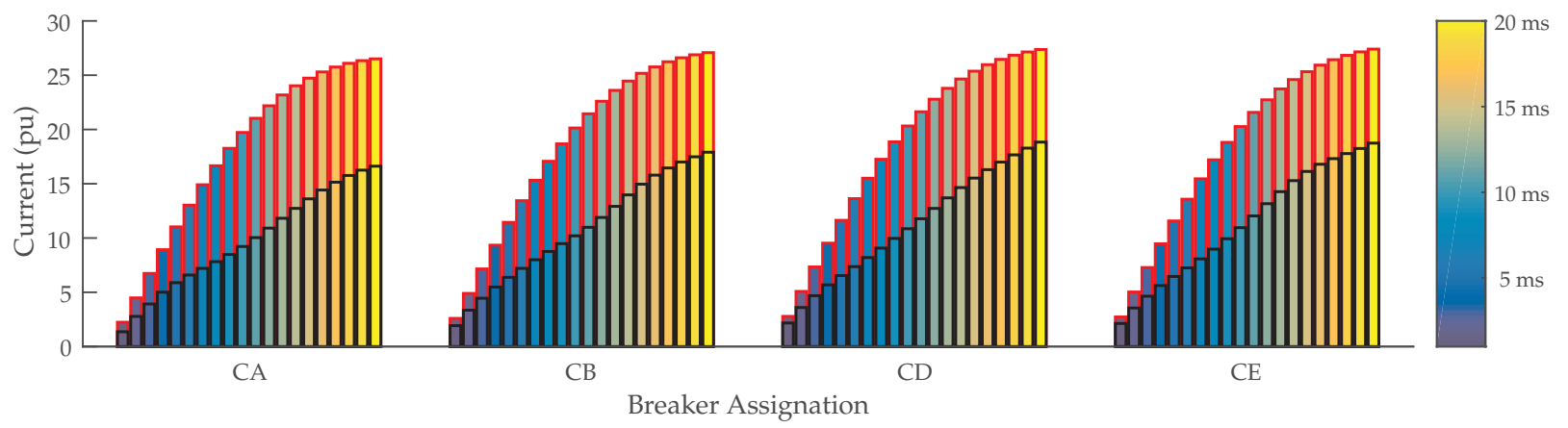

Fig. 9: Summary of five terminal fault studies; Aggregated peak fault current seen at the breaker where converter C is an AAC (black outline) and an MMC (red outline)

[4] SGRI, "Sgri launches worlds first 200kv de circuit breaker" January 2015. [Online]. Available: http://www.cepri.com.cn/release/details_66_ 721.html

[5] M. Callavik, A. Blomberg, J. Häfner, and B. Jacobson, "The hybrid HVDC Breaker: An innovation breakthrough enabling reliable HVDC grid ," ABB Grid Systems, Technical paper..., 2012.

[6] C. Barker and R. Whitehouse, "An alternative approach to hvdc grid protection," in AC and DC Power Transmission (ACDC 2012), 10th IET International Conference on, Dec 2012, pp. 1-6.

[7] J. Sneath and A. Rajapakse, "Fault detection and interruption in an earthed hvdc grid using rocov and hybrid dc breakers," Power Delivery, IEEE Transactions on, vol. PP, no. 99, pp. 1-1, 2014.

[8] M. M. C. Merlin, T. C. Green, P. D. Mitcheson, D. R. Trainer, R. Critchley, W. Crookes, and F. Hassan, "The Alternate Arm Converter: A New Hybrid Multilevel Converter With DC-Fault Blocking Capability," Power Delivery, IEEE Transactions on, vol. 29, no. 1, pp. 310-317, Feb. 2014.

[9] M. Merlin, T. Green, P. Mitcheson, F. Moreno, K. Dyke, and D. Trainer, "Cell capacitor sizing in modular multilevel converters and hybrid topologies," in Power Electronics and Applications (EPE'14-ECCE Europe), 2014 16th European Conference on, Aug 2014, pp. 1-10.

[10] A. F. H. G. T. Q. M. J. Anders Gustafsson, Markus Saltzer, "The new $525 \mathrm{kV}$ extruded HVDC cable system," ABB Grid Systems, Technical Paper, 2014.

[11] P. S. M. S. H. G. H. R. A. Gustafsson, M. Jeroense, "New developments within the area of extruded HVDC cables," $A C$ and DC Power Transmission (ACDC 2015), 11th IET International Conference on, 2015.

[12] A. Beddard and M. Barnes, "Hvdc cable modelling for vsc-hvdc applications," in PES General Meeting - Conference Exposition, 2014 IEEE, July 2014, pp. 1-5.

[13] H. De Silva, A. Gole, and L. Wedepohl, "Accurate electromagnetic transient simulations of hvdc cables and overhead transmission lines," in Proc. Int. Power Syst. Transients Conf, 2007.

[14] O. Ramos Leanos, "Wideband line/cable models for real-time and offline simulations of electromagnetic transients," Ph.D. dissertation, École Polytechnique de Montréal, 2013.

[15] M. B. R. S. A. B. O Cwikowski, B Chang, "Fault current testing envelopes for vsc hvdc circuit breakers," in $A C$ and DC Power Transmission (ACDC 2015), 11th IET International Conference on, Feburary 2015, pp. 1-6. 